\title{
Atherogenic Indices and HDL Particle Size as Laboratory Parameters to Evaluate Cardiovascular Risk in the Presence of Dyslipidemia
}

\author{
Ana Paula C. Santos' ${ }^{1}$ Marcos S. Vieira ${ }^{2}$, Débora F. Deus ${ }^{3}$, Rogério Jorge B. de Oliveira ${ }^{2}$, \\ Aleksandra T. Morikawa ${ }^{3}$, Roque Aras4, Ajax M. Atta5, Fabio D. Couto6, \\ Raul C. Maranhão ${ }^{3,7}$, Ricardo D. Couto ${ }^{1,4,8}$ \\ ${ }^{1}$ Clinical Biochemistry Laboratory, Department of Clinical and Toxicological Analysis, Faculty of Pharmacy, \\ Federal University of Bahia/UFBA, Salvador, Brazil \\ ${ }^{2}$ Naval Hospital of Salvador, Brazilian Marine Forces, Salvador, Brazil \\ ${ }^{3}$ Lipid Metabolism Laboratory of the Heart Institute (InCor-Clinical Hospital of Medical School), Faculty of \\ Pharmacy, University of São Paulo/USP, São Paulo, Brazil \\ ${ }^{4}$ Ana Neri Hospital, SESAB and Federal University of Bahia/UFBA Faculty of Medicine, Salvador, Brazil \\ ${ }^{5}$ Laboratory of Research in Immunology (LAPIM), Department of Clinical and Toxicological Analysis, Faculty of \\ Pharmacy, Federal University of Bahia/UFBA, Salvador, Brazil \\ ${ }^{6}$ Laboratory of Molecular Biology and Genetics at Center of Agricultural, Environmental and Biological Sciences \\ (CCAAB-UFRB), Cruz das Almas, Brazil \\ ${ }^{7}$ Faculty of Pharmaceutical Sciences, Clinical Chemistry Department, University of São Paulo/USP, São Paulo, \\ Brazil \\ ${ }^{8}$ Central Clinical Laboratory of Professor Edgar Santos University Hospital, Federal University of Bahia/UFBA, \\ Salvador, Brazil \\ Email: rdc@ufba.br
}

Received 3 February 2014; revised 3 March 2014; accepted 10 March 2014

Copyright (C 2014 by authors and Scientific Research Publishing Inc.

This work is licensed under the Creative Commons Attribution International License (CC BY).

http://creativecommons.org/licenses/by/4.0/

(c) (i) Open Access

\section{Abstract}

Dyslipidemia may influence enzymes and transfer proteins needed to the lipoprotein particle remodeling. Calculated indices and evaluation of lipoprotein particle size have widely been used to predict cardiovascular risk. The aim of this study was to evaluate HDL particle size and LDL particle size estimate based on TG/HDL-C as well as apoB/apoA-I ratio as possible marker and atherogenic indices, respectively, of cardiovascular disease risk in the presence of dyslipidemia. We evaluated 100 individuals of both gender, without treatment with lipid-lowering drugs, 27 normolipidemic and 73 dyslipidemic, such as isolated hypercholesterolemia $(n=16)$, isolated 
hypertriglyceridemia $(n=17)$, low HDL-C $(n=26)$ and mixed dyslipidemia $(n=14)$. The HDL particle size did not differ between groups. The TG/HDL-C ratio was higher in groups with isolated hypertriglyceridemia $(4.2 \pm 1.5)$, low HDL-C $(5.2 \pm 3.1)$ and mixed dyslipidemia $(5.3 \pm 1.6)$. The apoB/apoA-I ratio was increased in all groups of dyslipidemia (apoB/apoA-I > 0.5) when compared to normolipidemic $(\mathrm{apoB} / \mathrm{apo} A-\mathrm{I}=0.5, \mathrm{p}<0.001)$. There was a positive linear correlation between the TG/HDL-C ratio and the apoB/apoA-I ratio in low HDL-C group $(r=0.507, p=0.008$, Spearman). The results suggest that the evaluations of lipoproteins particles remodeling markers and the use of calculated indices may contribute to the evaluation of cardiovascular disease risk when dyslipidemia take place.

\section{Keywords}

\section{Dyslipidemia, Atherogenic Indices, Cardiovascular Risk}

\section{Introduction}

Dyslipidemia may be characterized by the presence of abnormal serum lipoprotein concentrations due to changes in the production, catabolism, clearance and disorders of lipid metabolism as a result of genetic and/or environmental factors [1]. The remodeling of lipoprotein particle is due to the action of enzymes and transfer proteins that participates in the metabolism of HDL, such as hepatic lipase (HL), phospholipid transfer protein (PLTP), cholesteryl ester transfer protein (CETP), lipoprotein lipase (LPL) and lecithin cholesterol acyltransferase (LCAT) [2]-[4]. Dyslipidemia may be negatively implicated in the enzymes and transfer proteins action mechanisms leading to changes in physical-chemical, structural and functional characteristics that, consequently, cause instability in the whole lipoprotein metabolism [5].

HDL particles show highly structure heterogeneity, intravascular metabolism and consequently antiatherogenic properties [6]. HDL shows different subfractions which can be identified based on the density, electrophoretic mobility, particle size and apolipoprotein (apo) composition [7]. The differences in size of these particles may be associated with the number of molecules (e.g., apo) in the surface and the concentration of esterified cholesterol in lipoprotein core [8]. The assessment of lipoprotein particles size has been the subject of many studies, since it contributes to cardiovascular risk evaluation. Numerous evidences suggest that cardioprotective properties of $\mathrm{HDL}$ are more associated with $\mathrm{HDL}_{2}$ fraction (larger) than $\mathrm{HDL}_{3}$ (smaller and denser) [9].

The LDL also shows particle size heterogeneity. It has two distinct phenotypes that can be distinguished by size, density, physico-chemical composition, metabolic behavior and atherogenicity. The phenotypes may be "A" (predominantly larger LDL) and "B" (predominance of small and dense LDL (sd LDL)) [10]. Smaller and denser particles are more atherogenic due to their higher ability to inter vessel wall, retention capacity and reduced affinity for physiological LDL receptor (LDL-r). So, they are more susceptible to oxidative modifications [11] [12], normally ascribed to higher plasmatic permanence time. Finally, sd LDL particles have intrinsic features that may slow down metabolism and bring intra/extravascular disturbance when compared with LDL of normal size, and contribute to great atherogenicity [13]. To estimate the presence of sd LDL it is beneficial to quantify the levels of TG and HDL-C, because the quantity, concentration and type of these particles are positively correlated with plasma levels of TG and negatively correlated to HDL-C. The sd LDL estimate is calculated by TG/HDL-C ratio. Ratios higher than 2.0 are indicative of sd LDL (particles $\leq 25.5 \mathrm{~nm}$ ) [11].

Besides evaluating lipoprotein particles (HDL and LDL) remodeling, the present study evaluates the apoB/ apoA-I ratio in different groups of dyslipidemia, according to laboratorial criteria of the IV Brazilian Guidelines for dyslipidemia and atherosclerosis prevention in normolipidemic (Normo); isolated hypercholesterolemia (HCT) (LDL-C $\geq 160 \mathrm{mg} / \mathrm{dL}$ ); isolated hypertriglyceridemia (HTG) (TG $\geq 150 \mathrm{mg} / \mathrm{dL}$ ), Low HDL cholesterol (Low HDL-C) (males $<40 \mathrm{mg} / \mathrm{dL}$ and females $<40 \mathrm{mg} / \mathrm{dL}$ ), and mixed dyslipidemia (Mixed) (LDL-C $\geq 160$ $\mathrm{mg} / \mathrm{dL}$ and $\mathrm{TG} \geq 150 \mathrm{mg} / \mathrm{dL}$ ) [14]. The measurement of apoB in atherogenic particles (QM, VLDL, IDL and LDL) and apoA-I in antiatherogenic particles (HDL) can improve the Prediction risk of coronary artery disease [15]. The apoB has a more significant value when compared with LDL-C levels to predict the imminent risk of fatal myocardial infarction. LDL-C concentration alone, as cardiovascular risk indicator, has less predictive value when 
compared to apoB and apoA-I concentration, and apoB/apoA-I ratio [16]. The evaluation of apoB/apoA-I ratio is an important step to early detection and prevention of cardiovascular risk [15].

The aim of this study was to evaluate the use of HDL particle size, sd LDL (TG/HDL-C) estimate and apoB/ apoA-I ratio, atherogenic indices, as possible markers of cardiovascular risk in the presence of dyslipidemia.

\section{Material and Methods}

\subsection{Patients}

One hundred individuals of both genders (27 normolipidemic and 73 dyslipidemic), between 40 - 70 years old, admitted to the Clinical Biochemistry Laboratory, Faculty of Pharmacy—Federal University of Bahia (UFBA) were selected by convenience to blood collection. Individuals were allocated according to information at epidemiological questionnaire such as sedentary (75 \%), dyslipidemia (73\%), hypertension (43\%), presence of cardiovascular events in first and second degree relatives (38\%), alcohol consumption (20\%), diabetes (9\%) and smoking (5\%). The experimental protocol was approved by the ethical committee of Climério de Oliveira Maternity Hospital and a written informed consent was given by all participants. The participants did not have any renal or hepatic dysfunction and have not been treated with lipid-lowering drugs.

\subsection{Biochemical Determinations}

Blood samples were collected after 12-hour fasting. The plasma total cholesterol and TG levels were determined by enzymatic colorimetric methods using automated equipment LABMAX 240 (Labtest Diagnostic SA, Brazil). HDL-C was determined using homogeneous method (HDL LE, Reference 98, Labtest Diagnostic SA, Brazil). Briefly, the above methodology utilizes two reagents; the first, a polyanion, aggregates to the apoB containing lipoproteins as stable complexes, and the second, a detergent mixed with cholesterol reaction enzymes, solubilizes and act upon the unprotected HDL cholesterol, respectively. The reagents used to biochemical studies were provided by Labtest (Labtest Diagnostic SA, Brazil). The LDL cholesterol levels were estimated by the Friedewald formula [17], and VLDL cholesterol as triglycerides divided by five.

\subsection{HDL Particle Size Determination}

The HDL particle size diameters were measured by laser light scattering (LLS), using a ZetaPALS Zeta Potential Analyzer (ZetaPALS; Brookhaven Instruments, Holtsville, NY) as previously described by our group [7]. $10 \mathrm{~mL}$ of blood were collected from all subjects by a vacuum dispositive into a glass tube containing EDTA $\left(\mathrm{k} 3 \mathrm{E}\right.$ k3-EDTA, VACUETTE ${ }^{\circledR}$ ). EDTA plasma was then obtained by centrifugation at $4^{\circ} \mathrm{C}$ for $15 \mathrm{~min}$ at $1250 \mathrm{~g}$. For the isolation of HDL for subsequent sizing by LLS, we precipitate apoB containing lipoproteins with a solution of polyethylene glycol (PEG) 8000 (400 g/L) in $0.2 \mathrm{~mol} / \mathrm{L}$ glycine buffer adjusted to pH 10 with $\mathrm{NaOH}$, by mixing $500 \mu \mathrm{L}$ of the precipitating solution to $500 \mu \mathrm{L}$ of EDTA plasma and stirred in a vortex-mixer for $30 \mathrm{~s}$. Samples were then centrifuged at $1800 \mathrm{~g}$ for $10 \mathrm{~min}$ at $25^{\circ} \mathrm{C}$ in an Eppendorf ${ }^{\circledR}$ microcentrifuge. A $0.5 \mathrm{~mL}$ portion of the supernatant was added to $1.5 \mathrm{~mL}$ of $\mathrm{NaCl}(10 \mathrm{mmol} / \mathrm{L})$, passed through a $0.22 \mu \mathrm{m}$ filter (Millipore Products Division) just to exclude undesirable particles, and dispensed into a disposable cuvette. The ZetaPALS Zeta Potential Analyzer uses a $29 \mathrm{~mW}$ helium-neon laser at $658 \mathrm{~nm}$ to excite the samples. Scattered light is collected at an angle of $90^{\circ}$ by a photon-counting photomultiplier tube and is then directed to a correlator. The BIC particle sizing software derives particle sizes from the correlator function. Results of each sample were expressed as the mean, which is the harmonic intensity-averaged particle diameter. All experiments were performed at $25^{\circ} \mathrm{C}$, and the results are expressed by means of five runs of 2 min each.

\subsection{ApoB and ApoA-I Concentration}

The apoB and apoA-I levels were determined by immunonephelometry using an automated analyzer, IMMAGE $^{\circledR}$ (Beckman Coulter, USA), by the measurement of light scattered or reflected when radiant energy passing through a solution and encounters a molecule in elastic collision. The resultant light is detected in a different path of the direct transmitted light.

\subsection{Estimation of LDL Particle Size}

LDL particle size was estimated by TG/HDL-C ratios. Ratios higher than 2.0 were considered indicative of sd 
$\operatorname{LDL}(\leq 25.5 \mathrm{~nm})[11]$.

\subsection{Statistical Analyses}

Data normality was tested by D’Agostino procedure, a tests for normal distribution in goodness-of-fit techniques from intuitive biostatistics, and equal variances were verified by Bartlett's test. Data are expressed as mean \pm SD. The inferential analysis was followed by one way-ANOVA and Tukey-Kramer post-test, used to compare the differences between the biochemical parameters, HDL particle size and apoB/apoA-I ratio. Kruskal-Wallis test followed by Dunns post-test was used to compare TG/HDL-C ratio differences among groups. The Spearman coefficient was used to analyze the linear correlation between TG/HDL-C and apoB/apoA-I ratios. Outlier detection was tested by Grubbs test. All tested data were considered significant when critical value (p) was under 0.05. The statistical analyses were done at GraphPad Prism version 5.01 (USA) statistical packages.

\section{Results}

Table 1 shows the descriptive analysis of individuals by gender, age and classification of dyslipidemic groups according criteria of IV Brazilian Guidelines for dyslipidemia and atherosclerosis prevention (2007) [14].

Table 2 shows the results of biochemical parameter concentrations value such as lipid profile, urea, creatinine, AST, ALT and glucose between normolipidemic and dyslipidemic groups. It's important to remark that participating individuals did not use lipid-lowering drugs at the time of blood sampling.

Figure 1 shows the results of HDL particle size. The results were not different between groups $(\mathrm{p}>0.05)$. The HDL particle size $(\mathrm{nm})$ values are shown by mean \pm SD: Normo $(13.0 \pm 1.0)$; isolated HCT (13.5 \pm 2.5$)$; isolated HTG (11.7 \pm 2.5$)$, low HDL-C (12.6 \pm 1.4$)$ and mixed dyslipidemia (11.6 \pm 1.3$)$.

As shown in Figure 2, the groups with isolated HTG, low HDL-C and mixed dyslipidemia had higher TG/HDL-C ratios. These groups may have a higher proportion of sd LDL when compared with normolipidemic group $(\mathrm{n}=99, \mathrm{p}<0.001)$. The values obtained are shown as mean \pm SD: Normo $(1.7 \pm 0.7)$; isolated HCT $(1.9 \pm$ 0.7); isolated HTG (4.2 \pm 1.5$)$, low HDL-C (5.2 \pm 3.1$)$ and mixed dyslipidemia (5.3 \pm 1.6$)$.

To help the evaluation of cardiovascular risk, apoB/apoA-I ratio was calculated (Figure 3). The dyslipidemic patients had a higher apoB/apoA-I ratio when compared to normolipidemic. The values obtained are shown as mean \pm SD: Normo $(0.5 \pm 0.1)$; isolated HCT $(0.7 \pm 0.2)$; isolated HTG $(0.67 \pm 0,1)$, low HDL-C $(0.8 \pm 0.2)$ and mixed dyslipidemia $(0.9 \pm 0.2)$.

Figure 4 shows the results of the linear correlation analysis between TG/HDL-C and apoB/apoA-I ratio in low HDL-C group. The TG/HDL-C ratio was positively correlated with apoB/apoA-I ratio $(r=0.507, p=0.008$; Spearman).

\section{Discussion}

In the study, patients were grouped by laboratorial and etiologic criteria to evaluate lipid profile based on local regulations (Table 1) according to IV Brazilian Guidelines for dyslipidemia and atherosclerosis prevention (2007) [14]. Table 2 shows the results of lipid, renal and hepatic profiles that were important to validate inclusion and exclusion criteria. The lipid profile parameters concentrations from dyslipidemic were statistically dif-

Table 1. Descriptive analysis of individuals by gender, age and classification of dyslipidemic according to IV Brazilian Guidelines for dyslipidemia and atherosclerosis prevention criteria (2007).

\begin{tabular}{|c|c|c|c|c|c|c|}
\hline & \multirow{2}{*}{ Normo } & \multirow{2}{*}{$\begin{array}{c}\text { Isolated } \\
\text { HCT }\end{array}$} & \multirow{2}{*}{$\begin{array}{c}\text { Isolated } \\
\text { HTG }\end{array}$} & \multirow{2}{*}{$\begin{array}{c}\text { Low } \\
\text { HDL-C }\end{array}$} & \multirow{2}{*}{ Mixed } & \multirow{2}{*}{$\mathbf{n}$} \\
\hline & & & & & & \\
\hline (n) & $(n=27)$ & $(n=16)$ & $(n=17)$ & $(n=26)$ & $(n=14)$ & 100 \\
\hline Female & 24 & 15 & 10 & 10 & 05 & 64 \\
\hline Age, years & $51 \pm 8$ & $52 \pm 9$ & $47 \pm 8$ & $47 \pm 9$ & $59 \pm 11$ & \\
\hline Male & 03 & 01 & 07 & 16 & 09 & 36 \\
\hline Age, years & $53 \pm 3$ & 45 & $54 \pm 12$ & $54 \pm 12$ & $57 \pm 7$ & \\
\hline
\end{tabular}

Results are expressed as means \pm SD. Normo: normolipidemic; HCT: isolated hypercholesterolemia (LDL-C $\geq 160$ mg/dL); HTG: isolated hypertriglyceridemia (TG $\geq 150 \mathrm{mg} / \mathrm{dL}$ ); Low HDL-C: Low HDL cholesterol (males < $40 \mathrm{mg} / \mathrm{dL}$ and females $<40 \mathrm{mg} / \mathrm{dL}$ ); Mixed: mixed dyslipidemia (LDL-C $\geq 160 \mathrm{mg} / \mathrm{dL}$ and $\mathrm{TG} \geq 150 \mathrm{mg} / \mathrm{dL}$ ). 
Table 2. Biochemical parameters concentrations value such lipid profile, urea, creatinine, AST, ALT and glucose between normolipidemic and dyslipidemic groups.

\begin{tabular}{cccccc}
\hline Biochemical parameters & $\begin{array}{c}\text { Normo } \\
(\mathbf{n}=\mathbf{2 8})\end{array}$ & $\begin{array}{c}\text { Isolated } \\
\text { HCT } \\
\mathbf{( n = 1 6 )}\end{array}$ & $\begin{array}{c}\text { Isolated } \\
\text { HTG } \\
\mathbf{( n = 1 7 )}\end{array}$ & $\begin{array}{c}\text { How } \\
(\mathbf{n}=\mathbf{2 6})\end{array}$ & $\begin{array}{c}\text { Mixed } \\
(\mathbf{n}=\mathbf{1 4})\end{array}$ \\
\hline TC (mg/dL) & $188 \pm 26$ & $273 \pm 36^{* * *}$ & $215 \pm 21$ & $187 \pm 45$ & $283 \pm 32^{* * *}$ \\
TG (mg/dL) & $90 \pm 31$ & $101 \pm 30$ & $205 \pm 50^{* * *}$ & $207 \pm 50^{* * *}$ & $233 \pm 55^{* * *}$ \\
HDL-C (mg/dL) & $53 \pm 7$ & $53 \pm 10$ & $49 \pm 7$ & $34 \pm 4^{* * *}$ & $44 \pm 8^{*}$ \\
LDL-C (mg/dL) & $118 \pm 23$ & $200 \pm 33^{* * *}$ & $125 \pm 21$ & $111 \pm 39$ & $192 \pm 25^{* * *}$ \\
VLDL-C (mg/dL) & $18 \pm 6$ & $20 \pm 6$ & $41 \pm 13^{* * *}$ & $40 \pm 30^{* * *}$ & $46 \pm 11^{* * *}$ \\
apoA(mg/dL) & $161 \pm 24^{* * *}$ & $172 \pm 31^{* * *}$ & $172 \pm 27^{* * *}$ & $127 \pm 25^{* * *}$ & $159 \pm 21^{* * *}$ \\
apoB (mg/dL) & $81 \pm 16^{* * *}$ & $122 \pm 24^{* * *}$ & $111 \pm 18^{* * *}$ & $99 \pm 32^{* *}$ & $154 \pm 26^{* * *}$ \\
Glucose (mg/dL) & $93 \pm 14$ & $92 \pm 12$ & $103 \pm 17$ & $105 \pm 27$ & $102 \pm 13$ \\
Urea (mg/dL) & $25 \pm 6$ & $27 \pm 8$ & $36 \pm 4^{* * *}$ & $28 \pm 8$ & $34 \pm 10^{*}$ \\
Creatinine (mg/dL) & $0.9 \pm 0.1$ & $0.9 \pm 0.1$ & $1.0 \pm 0.1$ & $1.1 \pm 0.3$ & $1.1 \pm 0.2$ \\
AST (mg/dL) & $29 \pm 8$ & $24 \pm 6$ & $26 \pm 5$ & $29 \pm 8$ & $30 \pm 7$ \\
ALT (mg/dL) & $24 \pm 12$ & $19 \pm 7$ & $23 \pm 6$ & $27 \pm 12$ & $29 \pm 8$ \\
\hline
\end{tabular}

Results are expressed as means \pm SD. ANOVA, Tukey-Kramer post test, $\mathrm{p}<0.05\left({ }^{*}\right)$; $\mathrm{p}<0.01\left(^{* *}\right), \mathrm{p}<0.001\left(^{* * *}\right)$. Normo: normolipidemic; HCT: hypercholesterolemia; HTG: hypertriglyceridemia; HDL-C: HDL cholesterol; Mixed: mixed dyslipidemia. The differences observed on apoA analyses were against Low HDL-C parameter. The differences observed on apoB analyses were against Normo parameter.

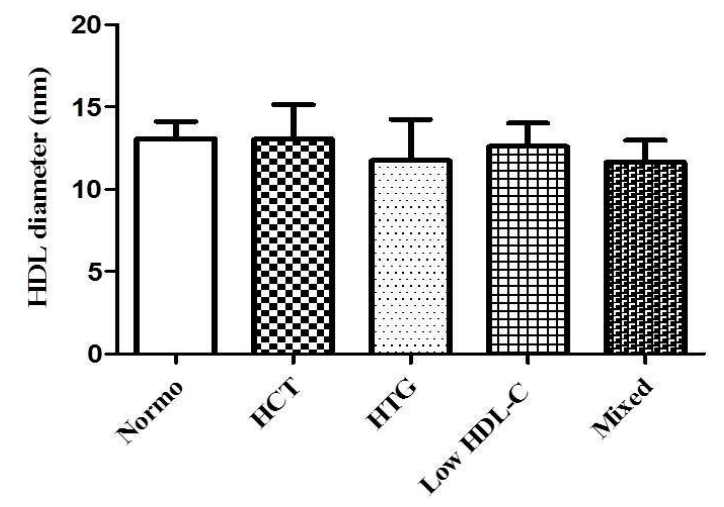

Figure 1. HDL diameter (nm) in different groups of dyslipidemia determined by laser-light scattering (LLS) described by Lima and Maranhão, 2004. One-way ANOVA, Tukey-Kramer post test, nonsignificant (n.s.), $\mathrm{p}>0.05$.

ferent $(\mathrm{p}<0.05$ ) when compared to normolipidemic group. The fact that the participating individuals did not use lipid-lowering drugs at the time of sampling was important to exclude treatment interference on lipid metabolism, a really important aspect not found in several important published studies [18] [19].

The HDL particle size does not differ among the groups (Figure 1). Several plasma factors alter HDL particle size, in the processes termed remodeling, which include the activity of LCAT, CETP, PLTP plasma transfer proteins, and enzymes (e.g. LPL, HL). These transfer proteins influences free cholesterol, esterified cholesterol, phospholipids content on HDL's particle [20]. Differences in particle size also may be associated with the number of molecules of apo on lipoprotein surface [8]. These parameters did not influence significantly the HDL size in this study. Some studies have shown that small HDL particles ( $\mathrm{HDL}_{3}$ ) contribute to increased cardiovascular risk, whereas the large HDL particles $\left(\mathrm{HDL}_{2}\right)$ are associated with a decreased risk and they have potent antiatherogenic properties [9] [21]. The HDL's particle size has been a target of many studies based on evaluation of cardiovascular risk. The study by Azevedo et al. [22] showed that patients with coronary artery disease (CAD) had smaller HDL particles $(8.7 \pm 0.7 \mathrm{~nm})$ than non-CAD group $(9.7 \pm 1.6 \mathrm{~nm})$. In another study, was observed that high TG levels in patients with CAD were significantly associated with low $\mathrm{HDL}_{2}$ (larger particles) with 


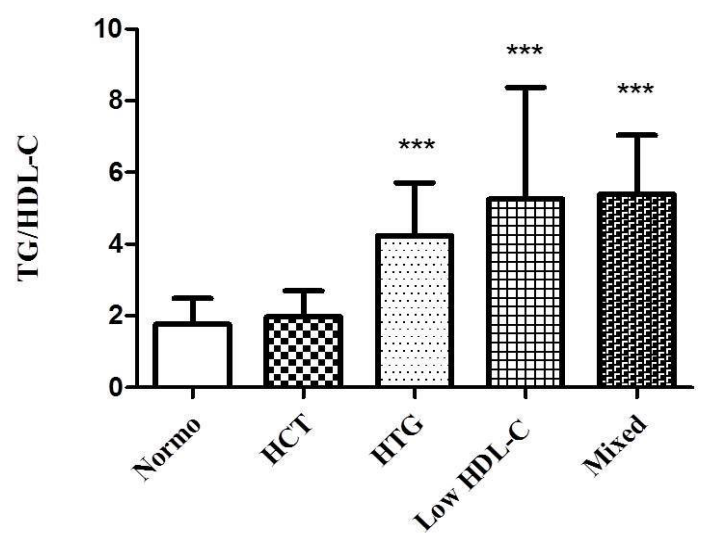

Figure 2. TG/HDL-C ratio in different groups of dyslipidemia. Kruskal Wallis test, Dunn's post test ( $\mathrm{p}<$ $0.001^{* * *}$ ). Normo vs. HCT ( $>>0.05$, n.s.); Normo vs. HTG (p $<0.001^{* * *}$ ); Normo vs. Low-HDL-C (p < $\left.0.001^{* * * *}\right)$; Normo vs. Mixed $\left(\mathrm{p}<0.001^{* * *}\right)$. In low HDL-C group, Grubb’s test was performed to detect outlier.

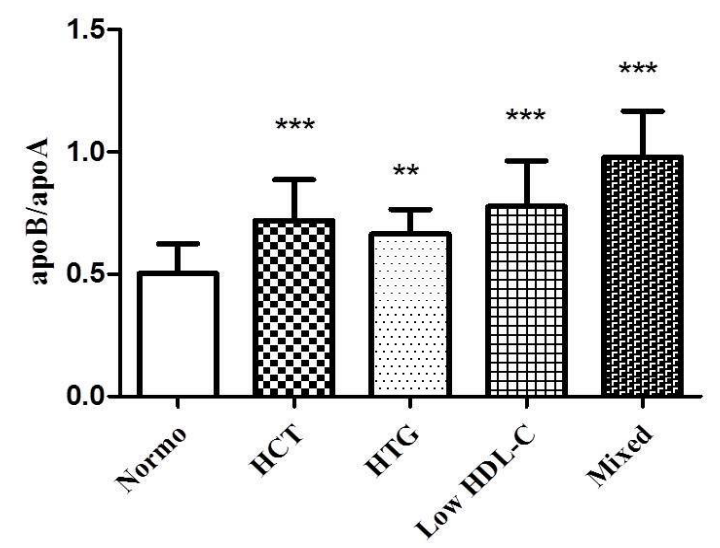

Figure 3. Comparison of apoB/apoA-I ratio in different groups of dyslipidemia. One-way ANOVA, Tukey-Kramer post test $\left(\mathrm{p}<0.001^{* * *}\right)$. Normo vs. HCT ( $<<$ $0.001^{* * * *}$ ); Normo vs. HTG $\left(\mathrm{p}<0.01^{* *}\right)$; Normo vs. Low HDL-C $\left(\mathrm{p}<0.001^{* * *}\right)$; Normo vs. Mixed $\left(\mathrm{p}<0.001^{* * *}\right)$.

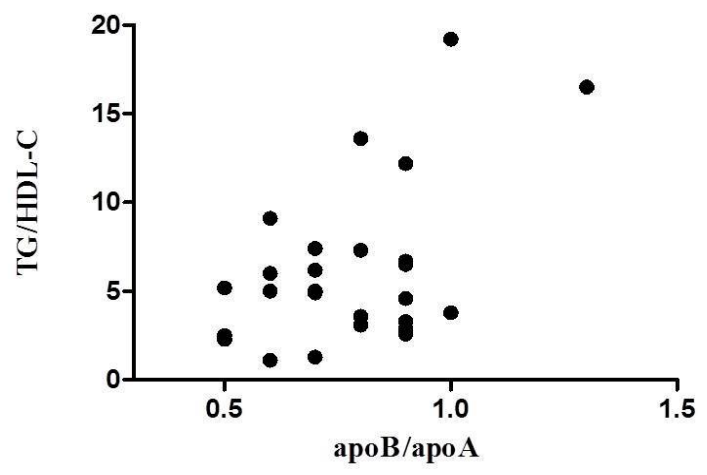

Figure 4. Linear correlation analysis between TG/ HDL$\mathrm{C}$ and apoB/apoA-I ratios in low HDL-C group ( $\mathrm{r}=$ $0.507, p=0.008$; Spearman). Grubb’s test was performed to detect outlier. 
predominance of $\mathrm{HDL}_{3}$ particles (smaller particles) [23]. Pascot et al. [24] shows that dyslipidemic state like high TG and low HDL-C, are strongly correlated to reduced HDL particle size. These findings were not reproduced in our study since the dyslipidemic groups had HDL's particle size similar to normolipidemic group.

The TG/HDL-C ratio is a combined parameter, estimated atherogenic index, that facilitates the assessment of the quality and presence of abnormal lipoproteins that corresponds to the sd LDL, which suggests a high risk of developing atherosclerosis [11]. In this study the patients who had a higher TG/HDL-C ratio like the isolated HTG group, low HDL-C and mixed dyslipidemia (Figure 2) correlates to a higher proportion of sd LDL, which is more atherogenic. The values of TG/HDL-C ratio in these groups estimate that LDL's particle sizes diameter is under $25.5 \mathrm{~nm}$. Sd LDL is considered an important cardiovascular disease risk marker [25]. Therefore, preventive measurements are necessary to control high TG levels and low HDL-C, mainly when associated with phenotype B (atherogenic). Approximately 75\% of the small LDL groups, demonstrated by polyacrylamide gel electrophoresis, gold standard, showed TG/HDL-C ratios higher than 2.0 [11]. The TG and HDL-C levels are the major determinants of the variability in the LDL size, which together explain $67 \%$ of variability in LDL size [26]. The presence of sd LDL is positively correlated with TG levels $(r=0.6, p<0.0001)$ and negatively with HDL-C $(r=-0.56, \mathrm{p}<0.0001)$ [27]. Abnormalities in the lipid metabolism such as high TG and low HDL-C levels affect the LDL particle size, density and its composition [28]. The use of TG/HDL-C ratio may be a strong and independent predictor of acute myocardial infarction, better than the TC/HDL-C and LDL-C/HDL-C ratios [29].

The mixed dyslipidemia group showed a higher apoB/apoA-I ratio when compared to other groups (Figure 3). Patients with mixed dyslipidemia have high TG and TC levels which are present in atherogenic lipoproteins like VLDL and LDL, which contain apoB. High apoB levels and low apoA-I levels, in other words, high apoB/ apoA-I ratio are strong predictors of cardiovascular risk. They have greater power in predicting risk when compared to serum LDL-C, TC and TG [15]. The apoB/apoA-I ratio represents the proportion of apoB-containing particles rich in cholesterol (atherogenic) and particles containing apoA-I (anti-atherogenic). Moreover apoB/ apoA-I ratios are also useful indicators of lipid-lowering therapy [30]. In this study, the linear correlation of apoB/apoA-I with TG/HDL-C (Figure 4) $(r=0.507, \mathrm{p}=0.008$, Spearmn) showed a directly proportional relationship, indicating the presence of sd LDL and high risk of developing atherosclerosis in low HDL-C studied group. The Bogavac-Stanojevic's study [31] revealed that the apolipoproteins ratio was a better marker than lipids/lipoproteins ratios; however, the differences between their discriminating abilities were not statistically significant. Both are risk ratios and they are important parameters used to evaluate cardiovascular risk and useful markers for predicting CAD [31].

\section{Conclusion}

The study evaluates the presence of cardiovascular risk markers in dyslipidemia. Based on the observation, the dyslipidemia should not importantly influence HDL particle size while comparing normolipidemic and dyslipdemic groups without treatment with lipid-lowering drugs. The estimated LDL particle size was obtained by TG/HDL-C ratio in patients with dyslipidemia, mainly in the groups with isolated HTG, low HDL-C and mixed dyslipidemia, have a larger proportion of sd LDL, or rather, more atherogenic particles concentration that provide higher cardiovascular risk. In this study it was also concluded that patients with dyslipidemia had higher apoB/apoA-I ratio, higher atherogenic particles concentration and lower concentrations of protector lipoproteins. Thus, the results suggest that evaluation of remodeling of lipoprotein particles (HDL and LDL) as well as the use of calculated indices such apoB/apoA-I, TG/HDL-C ratios are important parameters that contribute to cardiovascular risk evaluation in the presence of dyslipidemia.

\section{Conflict of Interest}

There is no conflict of interest for this study.

\section{Acknowledgements}

Foundation for Research Support of the State of Bahia-FAPESB/SESAB/MS/CNPq; Foundation of Research Support and Extension—FAPEX/UFBA; Clinical Biochemistry Laboratory of Faculty of Pharmacy—Federal University of Bahia; Central Clinical Laboratory of Professor Edgar Santos University Hospital—Federal University of Bahia; Lipid Metabolism Laboratory of the Heart Institute-InCor (Clinical Hospital, Faculty of 
Medicine), and Faculty of Pharmaceutical Sciences, University of São Paulo.

\section{References}

[1] Imes, C.C. and Austin, M.A. (2013) Low-Density Lipoprotein Cholesterol, Apolipoprotein B, and Risk of Coronary Heart Disease: From Familial Hyperlipidemia to Genomics. Biological Research for Nursing, 15, 292-308. http://dx.doi.org/10.1177/1099800412436967

[2] Carr, M.C., Ayyobi, A.F., Murdoch, S.J., Deeb, S.S. and Brunzell, J.D. (2002) Contribution of Hepatic Lipase, Lipoprotein Lipase, and Cholesteryl Ester Transfer Protein to LDL and HDL Heterogeneity in Healthy Women. Arteriosclerosis, Thrombosis, and Vascular Biology, 22, 667-673. http://dx.doi.org/10.1161/01.ATV.0000013284.47317.95

[3] Cheung, M.C., Wolfbauer, G., Deguchi, H., Fernandez, J.A., Griffin, J.H. and Albers, J.J. (2009) Human Plasma Phospholipid Transfer Protein Specific Activity Is Correlated with HDL Size: Implications for Lipoprotein Physiology. Biochimica et Biophysica Acta, 1791, 206-211. http://dx.doi.org/10.1016/j.bbalip.2008.12.010

[4] Deeb, S.S., Zambon, A., Carr, M.C., Ayyobi, A.F. and Brunzell, J.D. (2003) Hepatic Lipase and Dyslipidemia: Interactions among Genetic Variants, Obesity, Gender, and Diet. The Journal of Lipid Research, 44, 279-286. http://dx.doi.org/10.1194/jlr.R200017-JLR200

[5] Treguier, M., Briand, F., Boubacar, A., Andre, A., Magot, T., Nguyen, P., Krempf, M., Sulpice, T. and Ouguerram, K. (2001) Diet-Induced Dyslipidemia Impairs Reverse Cholesterol Transport in Hamsters. European Journal of Clinical Investigation, 41, 921-928. http://dx.doi.org/10.1111/j.1365-2362.2011.02478.x

[6] Kontush, A. and Chapman, M.J. (2006) Antiatherogenic Small, Dense HDL: Guardian Angel of the Arterial Wall? Nature Clinical Practice Cardiovascular Medicine, 3, 144-153. http://dx.doi.org/10.1038/ncpcardio0500

[7] Lima, E.S. and Maranhao, R.C. (2004) Rapid, Simple Laser-Light-Scattering Method for HDL Particle Sizing in Whole Plasma. Clinical Chemistry, 50, 1086-1088. http://dx.doi.org/10.1373/clinchem.2004.032383

[8] Barter, P., Kastelein, J., Nunn, A. and Hobbs, R. (2003) High-Density Lipoproteins (HDLs) and Atherosclerosis: The Unanswered Questions. Atheroscler, 168, 195-211. http://dx.doi.org/10.1016/S0021-9150(03)00006-6

[9] Arsenalt, B.J., Lemieux, I., Despres, J.P., Gagnon, P., Wareham, N.J., Stroes, E.S.J., Kastelein, J.J.P., Khaw, K. and Boekholdt, S.M. (2009) HDL Particle Size and the Risk of Coronary Heart Disease in Apparently Healthy Men and Women: The EPIC-Norfolk Prospective Population Study. Atheroscler, 206, 276-281. http://dx.doi.org/10.1016/j.atherosclerosis.2009.01.044

[10] Berneis, K.K. and Krauss, R.M. (2002) Metabolic Origins and Clinical Significance of LDL Heterogenity. The Journal of Lipid Research, 43, 1363-1379. http://dx.doi.org/10.1194/jlr.R200004-JLR200

[11] Maruyama, C., Imamura, K. and Teramoto, T. (2003) Assessment of LDL Particle Size by Triglyceride/HDL-Cholesterol Ratio in Non-Diabetic, Healthy Subjects without Proeminet Hyperlipidemia. Journal of Atherosclerosis and Thrombosis, 10, 186-191. http://dx.doi.org/10.5551/jat.10.186

[12] Lamarche, B., Andre, T., Moorjani, S., Cantin, B., Dagenais, G.R., Lupien, P.J. and Despres, J.P. (1997) Small, Dense Low-Density Lipoprotein Particles as a Predictor of the Risk of Ischemic Heart Disease in Men: Prospective Results from the Quebec Cardiovascular Study. Circulation, 95, 69-75. http://dx.doi.org/10.1161/01.CIR.95.1.69

[13] Sposito, A.C., Caramelli, B., Fonseca, F.A.H. and Bertolami, M.C. (2007) IV Brazilian Guideline for Dyslipidemia and Atherosclerosis Prevention: Department of Atherosclerosis of Brazilian Society of Cardiology. Arquivos Brasileiros de Cardiologia, 88, 2-19. http://dx.doi.org/10.1590/S0066-782X2007000700002

[14] Berneis, K., Shames, D.M., Blanche, P.J., La Belle, M., Rizzo, M. and Krauss, R.M. (2004) Plasma Clearance of Human Low-Density Lipoprotein in Humam Apolipoprotein B Transgenic Mice Is Related to Particle Diameter. Metabolism, 53, 483-487. http://dx.doi.org/10.1016/j.metabol.2003.10.031

[15] Walldius, G., Jungner, I., Holme, I., Aastveit, A.H., Kolar, W. and Steiner, E. (2001) High Apolipoprotein B, Low Apolipoprotein A-I, and Improvement in the Prediction of Fatal Myocardial Infaction (AMORIS Study): A Prospective Study. Lancet, 358, 2026-2033. http://dx.doi.org/10.1016/S0140-6736(01)07098-2

[16] Sniderman, A.D., Furberg, C.D., Keech, A., Lennep, V., Frohlich, J., Jungner, I. and Walldius, G. (2003) Apolipoproteins versus Lipids as Indices of Coronary Risk and as Targets for Statins Treatment. Lancet, 361, 777-780. http://dx.doi.org/10.1016/S0140-6736(03)12663-3

[17] Friedewald, W.T., Levy, R.I. and Fredrickson, D.S. (1972) Estimation of the Concentration of Low-Density Lipoprotein Cholesterol in Plasma, without Use of the Preparative Ultracentrifuge. Clinical Chemistry, 18, 499-502.

[18] Lo Prete, A.C., Dina, C.H., Azevedo, C.H., Puk, C.G., Lopes, N.H.M., Hueb, W.A. and Maranhao, R.C. (2009) In Vitro Simultaneous Transfer of Lipids to HDL in Coronary Artery Disease and in Statin Treatment. Lipids, 44, 917-924. http://dx.doi.org/10.1007/s11745-009-3342-2 
[19] Puk, C.G., Bocchi, E.A., Lo Prete, A.C., Ferreira, S.M.A., Stolf, N.A.G. and Maranhao, R.C. (2009) Transfer of Cholesterol and Other Lipids from a Lipid Nanoemulsion to High-Density Lipoprotein in Heart Transplant Patients. Journal of Heart and Lung Transplantation, 28, 1075-1080. http://dx.doi.org/10.1016/j.healun.2009.05.024

[20] Rye, K.A., Bursill, C.A., Lambert, G., Tabet, F. and Barter, P.J. (2009) The Metabolism and Anti-Atherogenic Properties of HDL. Journal of Lipid Research, 50, 195-200. http://dx.doi.org/10.1194/jlr.R800034-JLR200

[21] Jia, L., Long, S., Fu, M., Yan, B., Tian, W., Xu, Y. and Gou, L. (2006) Relationship between Total Cholesterol/HighDensity Lipoprotein Cholesterol Ratio, Triglyceride/High-Density Lipoprotein Cholesterol Ratio, and High-Density Lipoprotein Subclasses. Metabolism, 55, 1141-1148. http://dx.doi.org/10.1016/j.metabol.2006.04.004

[22] Azevedo, C.H.M., Wajngarten, M., Lo Prete, A.C., Diament, J. and Maranhao, R.C. (2011) Simultaneous Transfer of Cholesterol, Triglycerides, and Phospholipids to High-Density Lipoprotein in Aging Subjects with or without Coronary Artery Disease. Clinics, 66, 1543-1548.

[23] Syvanne, M., Ahola, M., Lahdenpera, S., Kahri, J., Kuusi, T., Virtanen, K.S. and Taskinen, M.R. (1995) High Density Lipoprotein Subfractions in Non-Insulin-Dependent Diabetes Mellitus and Coronary Artery Disease. Journal of Lipid Research, 36, 573-582.

[24] Pascot, A., Lemieux, I., Prud'homme, D., Tremblay, A., Nadeau, A., Couillard, C., Bergeron, J., Lamarche, B. and Despres, J.P. (2001) Reduced HDL Particle Size as an Additional Feature of the Atherogenic Dyslipidemia of Abdominal Obesity. Journal of Lipid Research, 42, 2007-2014.

[25] Da Luz, P.L., Favarato, D., Faria, J.R., Lemos, P. and Chagas, A.C.P. (2008) High Ratio of Triglycerides to HDL Cholesterol Predicts Extensive Coronary Disease. Clinics, 63, 427-432.

[26] Fagerberg, B., Hulthe, J., Bokemark, L. and Wikstrand, J. (2001) Low-Density Lipoprotein Particle Size, Insulin Resistence, and Proinsulin in Population Sample of 58-Year-Old-Men. Metabolism, 50, 120-124. http://dx.doi.org/10.1053/meta.2001.18570

[27] Tchernof, A., Lamarche, B., Prud’homme, D., Nadeau, A., Moorjani, S., Labrie, F., Lupien, P.J. and Despres, J.P. (1996) The Dense LDL Phenotype: Association with Plasma Lipoprotein Levels, Visceral Obesity, and Hyperinsulinemia in Men. Diabetes Care, 19, 629-637. http://dx.doi.org/10.2337/diacare.19.6.629

[28] Jeppesen, J., Hein, H.O., Suadican, P. and Gyntelberg, F. (2001) Low Triglycerides-High High-Density Lipoprotein Cholesterol and Risk of Ischemic Heart Disease. JAMA Internal Medicine, 161, 361-366. http://dx.doi.org/10.1001/archinte.161.3.361

[29] Vieira, E.A., Carvalho, W.A., Aras, R., Couto, F.D. and Couto, R.D. (2011) Triglycerides/HDL-C Ratio and High Sensible C-Reactive Protein to the Evaluation of Cardiovascular Risk. Jornal Brasileiro de Patologia e Medicina Laboratorial, 47, 113-118. http://dx.doi.org/10.1590/S1676-24442011000200004

[30] Walldius, G. and Jungner, I. (2004) Apolipoprotein B and Apolipoprtein A-I: Risk Indicators of Coronary Heart Disease and Targets for Lipid-Modifying Therapy. Journal of Internal Medicine, 255, 188-205. http://dx.doi.org/10.1046/j.1365-2796.2003.01276.x

[31] Stanojevic, N.B., Ivanovic, Z.J., Kalimanovska, V.S., Spasic, S. and Ostric, D.K. (2007) Lipid and Inflammatory Markers for the Prediction of Coronary Artery Disease: A Multi-Marker Approach. Clinical Biochemistry, 40, 1000-1006. http://dx.doi.org/10.1016/j.clinbiochem.2007.05.012 